\title{
High resolution sulfur isotopes from ice cores: new techniques and improved estimates of the volcanic forcing of climate
}

\author{
ANDREA BURKE ${ }^{1}$, HELEN M INNES ${ }^{1}$, MICHAEL SIGL ${ }^{2}$,
} JOSEPH MCCONNELL ${ }^{3}$, ROBERT STEELE ${ }^{1}$, JAMES W. B. RAE $^{1}$, CHRISTOPHER D. COATH $^{4}$, JAMIE LEWIS $^{4}$ AND TIM ELLIOTT $^{4}$

${ }^{1}$ University of St Andrews

${ }^{2}$ University of Bern

${ }^{3}$ Desert Research Institute

${ }^{4}$ University of Bristol

Presenting Author:ab276@st-andrews.ac.uk

Sulfate concentrations in ice cores provide a unique history of explosive volcanic eruptions, providing us with key insights into their climatic impact and long term frequency. Of particular interest are large explosive eruptions whose plumes made it to the stratosphere, as these eruptions afford sulfate aerosols the longest residence time and largest dispersion, and thus the greatest impact on radiative forcing and climate. Sulfur isotopes can be used to distinguish between stratospheric and tropospheric volcanic sulfate in ice cores since stratospheric sulfur aerosols are exposed to UV radiation, which imparts a mass independent fractionation (MIF). Measurement of sulfur isotopes in ice by multi-collector inductively coupled plasma mass spectrometry (MC-ICP-MS) has dramatically reduced sample size requirements for these measurements, allowing higher temporal resolution despite using less ice. These higher temporal resolution records provide crucial new information on the proportion of stratospheric sulfate deposited in the ice cores, allowing us to improve and correct the record of volcanic radiative forcing used in climate simulations of the past 2000 years. Further analytical developments with 'Proteus', a massfilter, collision cell MC-ICP-MS, have enabled measurement of quadruple sulfur isotopes $\left({ }^{32} \mathrm{~S},{ }^{33} \mathrm{~S},{ }^{34} \mathrm{~S},{ }^{36} \mathrm{~S}\right)$ on small samples, allowing us to measure the first ever high resolution $\Delta^{36} \mathrm{~S}$ values across a single volcanic peak in an ice core. These data provide important insights into the mechanism of MIF formation and sulfur oxidation in the stratosphere. 